\title{
0 Curso de Geologia da UFRJ perante as Diretrizes Curriculares Nacionais: possíveis impactos no perfil do egresso
}

\author{
The Geology Course of UFRJ against National Curriculum Guidelines: possible impacts in the egress profile
}

Amanda Goulart Rodrigues ${ }^{1}$

1- Laboratório de Geologia Sedimentar, Instituto de Geociências, UfRJ, Av. Athos da Silvelra Ramos 274, J2-20B - Cidade Universitária. CeP: 21941-919. Rio dE JANEIRO - RJ. E-MAIL: RODRIGUESAG.GEO@gmall.com

\begin{abstract}
The aim of this paper is to analyze the curriculum changes in the Geology undergraduate course of UFRJ against the National Curriculum Guidelines, to identify the possible impacts in the egress profile. A comparative and qualitative analysis of the curricula was done together with lecturers' interviews. The curriculum changes consist in: (1) the reduction of courses' theoretical-practical hours; (2) the inclusion of 420 hours of extension activities; (3) the inclusion of Supervised Internship and Healthy and Safe courses; and (4) the inclusion of theoretical hours in the Field Trip courses. Two impacts were identified: (1) better preparation to labor market, developing geologists more autonomous and attentive to social issues; and (2) detriment in basic conceptual training, making it difficult to solve complex geological problems. It is suggested the monitoring the implementation process semiannually, in order to assist in the detection of inconsistencies and in the planning of future revisions.
\end{abstract}

Manuscrito:

Recebido: 15/01/2018

Corrigido: $14 / 02 / 2018$

Aceito: $26 / 03 / 2018$

Citation: Rodrigues A.G. 2018. 0 Curso de Geologia da UFRJ perante as Diretrizes Curriculares Nacionais: possíveis impactos no perfil do egresso. Terræ Didatica na área de Geociências Terræ Didatica, 14(2):147-156. URL: http://www.ige. unicamp.br/terraedidatica/.

Keywords: Curriculum. Geosciences. Geologist.

\section{Introdução}

Os cursos pioneiros de Geologia das universidades brasileiras (Recife, Ouro Preto, São Paulo e Porto Alegre) foram resultado da criação em 1957 da Campanha de Formação de Geólogos (CAGE) pelo presidente Juscelino Kubitschek de Oliveira por meio do Decreto n ${ }^{\circ} 40.783$ de 18/01/1957 (Brasil 1957), em resposta à demanda por profissionais que soubessem prospectar recursos energéticos e minerais, elementos essenciais para diversos processos industriais em desenvolvimento no país naquela época (Assine 1994, Barroso et al. 2008).

Apesar de 60 anos de história, somente em 2015 foram instituídas as Diretrizes Curriculares Nacionais (DCNs) para os cursos de graduação em Geologia e em Engenharia Geológica pelo Ministério da Educação (Brasil 2015). A aprovação das DCNs tornou-se um marco nacional, na educação e, em especial, no ensino de Geologia, uma vez que possibilita a revisão das grades curriculares e dos procedimentos de ensino, como também orienta a criação de novos cursos (Menegat \& Carneiro
2014). Atualmente, existem 33 cursos de Geologia e 4 cursos de Engenharia Geológica no Brasil, de acordo com os dados do E-MEC (2017), sendo que somente 6 são ofertados por instituições privadas, e os demais, por instituições públicas (federais ou estaduais). Todos esses cursos, obrigatoriamente, tiveram prazo máximo de dois anos para adequar seus currículos às DCNs e implementá-los aos alunos ingressantes, como definido no Art. $10 \mathrm{da}$ Resolução CNE/CES 1/2015 (Brasil 2015).

As discussões a respeito das Diretrizes Curriculares dos cursos de Geologia e Engenharia Geológica iniciaram-se nos anos 2000, coordenadas pelo Fórum Nacional de Cursos de Geologia (FNCG), que é composto por coordenadores, dirigentes das unidades universitárias, docentes, profissionais, entidades estudantis, entidades profissionais e órgãos do governo envolvidos com a formação de geólogos no Brasil (Carneiro et al. 2014). Todo o registro dos encontros do FNCG foi publicado sequencialmente na revista Terre Didatica da Unicamp (e.g. Carneiro 2005a, 2014, Carneiro \& Assis 2005, 2006, Sobreira 2005, Assis et al. 2008, 
Fantinel et al. 2008a e 2008b). A versão inicial das DCNs para os cursos encontra-se em Nummer et al. (2005) e sua modificação está publicada em Fantinel et al. (2008a).

Os cursos serão organizados com base nos correspondentes projetos pedagógicos, que devem enunciar o perfil desejado para o formando; as competências e habilidades requeridas; os conteúdos curriculares; a organização curricular; o estágio supervisionado; o trabalho de curso; as atividades complementares; o acompanhamento e a avaliação (Resolução CNE/CES 1/2015, Art. 2º, Brasil 2015). Assim, as Instituições de Ensino Superior (IES) deverão formar um profissional com condição de trabalhar em qualquer área de atuação das Ciências Geológicas; que tenha capacidade para o trabalho de campo; domínio da linguagem técnica e comunicação plena com profissionais de outras áreas e com a sociedade; conhecimento de ciências exatas que permita abordagens quantitativas das informações geológicas e familiaridade com métodos e técnicas de informática (Nummer et al. 2005, Brasil 2012, Carneiro et al. 2014).

Diante desse cenário, o objetivo deste trabalho é realizar uma análise das mudanças ocorridas no currículo do curso de graduação em Geologia da Universidade Federal do Rio de Janeiro (UFRJ) frente às Diretrizes Curriculares Nacionais, com a finalidade de identificar quais serão os possíveis impactos positivos e negativos no perfil do egresso formado pela instituição.

\section{Materiais e métodos}

Para o presente trabalho, foi realizada uma análise comparativa e qualitativa da grade curricular atual (2017/1 - presente) e anterior (2010/1 - 2016/2) do curso de graduação em Geologia da UFRJ em relação a diversos atributos como: número de horas teóricas, práticas de laboratório e práticas de campo por período, carga horária das disciplinas obrigatórias por eixo didático, número de horas de extensão, entre outros. Em vias de possibilitar a comparação, foi necessário extrapolar os eixos didáticos para a grade curricular anterior, tendo em vista que estes foram definidos somente no currículo atual com o emprego das DCNs. O método comparativo seguiu os conceitos de Gil (2008) e a análise qualitativa foi aplicada segundo Laville \& Dionne (1999).

Adicionalmente, foi feita uma coleta de dados por meio de entrevistas estruturadas (sensu Gil
2008, Júnior \& Júnior 2011) com parte dos docentes (total de cinco), nomeados neste estudo por A, $\mathrm{B}, \mathrm{C}, \mathrm{D}$ e E, os quais participaram da construção do novo currículo e que estão participando da sua implementação. As perguntas (objetivas e dissertativas) basearam-se nas informações coletadas a partir da análise prévia das grades curriculares. Os temas abordados foram: (1) diminuição nas horas teórico-práticas e os impactos esperados; (2) inclusão de horas de extensão, suas principais atividades, envolvimento docente-discente e dificuldades de execução das propostas; (3) inclusão das disciplinas de Saúde e Segurança em Atividades de Geologia e Estágio Supervisionado, bem como seus benefícios; (4) mudanças na distribuição e carga horária das atividades de campo; (5) processo de implementação da nova grade curricular e suas dificuldades; e (6) mudanças curriculares e as consequências no perfil do egresso.

\section{Características gerais da grade curricular atual (2017/1 - presente)}

A grade curricular em implementação do curso de graduação em Geologia da UFRJ (Tab. Supl. 1) está estruturada em cinco eixos didáticos transversais ao longo dos dez períodos de duração do curso, são eles: Formação Básica, Formação Profissional Geral, Formação Profissional Específica, Fundamentação em Geociências, e Geologia e Sociedade. De acordo com o Projeto Pedagógico do Curso (PPC 2017), o eixo de Formação Básica contempla disciplinas obrigatórias que versam sobre as ciências básicas (Física, Química e Matemática). O eixo Geologia e Sociedade tem por objetivo prover uma visão mais ampla ao discente, que permita entender seu papel como profissional inserido na sociedade de forma a colaborar com sua transformação e melhoria. Já o eixo Fundamentação em Geociências visa fornecer conhecimentos fundamentais das Geociências por meio de conteúdos práticos e teóricos com o objetivo de criar uma base sólida para receber as disciplinas dos eixos Formação Profissional Geral e Formação Profissional Específica. O eixo Formação Profissional Geral é caracterizado por disciplinas obrigatórias presentes desde o primeiro semestre, que são exclusivas do curso de Geologia e dão ao discente uma formação mais generalista. E por fim, o eixo Formação Profissional Específica tem por objetivo refinar e aprofundar os conhecimentos geológicos, colaborando com a formação dos atributos profissionais. 
O curso possui 4.203 horas totais, sendo 978 horas $(23 \%)$ de atividades de campo e 420 horas $(10 \%)$ de extensão. A inclusão dessas horas de extensão se deve ao cumprimento das exigências da Lei Federal n. ${ }^{\circ}$ 13.005, de 25 de junho de 2014 (Plano Nacional de Educação 2014-2024, Meta 12.7, Brasil 2014) e das resoluções n. ${ }^{\circ}$ 02/2003 e 04/2014 do Conselho de Ensino de Graduação da UFRJ. Essas atividades de extensão, como descrito no PPC (2017), poderão ser desenvolvidas em programas, projetos ou eventos de extensão devidamente cadastrados na Pró-Reitoria de Extensão da UFRJ, coordenados por docentes ou servidores técnicos do Departamento de Geologia ou de qualquer outro Departamento do Instituto de Geociências ou mesmo de outras unidades. O tempo recomendado para concluir o curso é de 10 períodos, com a possibilidade de integralização com no mínimo de 8 períodos e no máximo de 15 períodos.

Houve uma redução dos pré-requisitos e co-requisitos na grade curricular atual, resultando em maior autonomia ao discente para escolher as disciplinas e sua ordem de disposição ao longo do curso. Contudo, essa medida poderá ser prejudicial para formação do geólogo, tendo em vista que os estudantes podem optar por disciplinas de etapas avançadas, negligenciando o recomendado pela IES. A organização curricular exerce significativa influência sobre o aprendizado (Gil 2015) e seu planejamento foi elaborado a fim de viabilizar um aproveitamento pleno dos saberes quando acessados na etapa do curso adequada.

Uma das novidades trazidas nessa grade curricular é a disciplina de Saúde e Segurança em Atividades de Geologia. Esta é recomendada para o primeiro período do curso, provendo conceitos básicos, fundamentais e avançados sobre saúde e segurança nas atividades desenvolvidas pelo geólogo, tanto em trabalhos de campo como em laboratório. A finalidade, de acordo com a súmula, é fornecer informações sobre saúde, segurança e meio ambiente, para que os futuros profissionais saibam utilizar na sua rotina laboral ferramentas de prevenção e remediação de acidentes.

A inclusão do estágio supervisionado é requisito das DCNs e consiste em um grande avanço em termos de formação profissional, pois dá a oportunidade ao aluno de estar em contato com o futuro ambiente de trabalho e possibilita a concretização do conhecimento teórico adquirido na universidade (Pimenta \& Lima 2012, Almeida \& Pimenta 2014). Para Almeida \& Pimenta (2014), é no período de estágio que os conhecimentos são ressignificados pelo aluno estagiário a partir de suas experiências pessoais em contato direto com o campo de trabalho. Os conhecimentos que, ao longo da vida profissional, vão sendo reconstruídos no exercício da profissão. A vivência de exemplos práticos aplicados a resolução de problemas geológicos reais e ligados a sociedade são aprendizados fundamentais para a consolidação da carreira como geólogo. No currículo atual, o estágio supervisionado foi incluído no $9^{\circ}$ período com 120 horas de prática de laboratório.

\section{Análise comparativa entre a grade curricular atual (2017/1 - presente) e a anterior (2010/1 - 2016/2)}

Um exame geral da distribuição e ênfase das disciplinas oferecidas nas grades curriculares mostra que o perfil do egresso desejado para essa instituição é o generalista, ou seja, o geólogo sairá com uma formação geral para atuar em qualquer área das Geociências. No entanto, se o discente desejar, poderá escolher disciplinas optativas que o auxiliarão no processo de profissionalização, uma vez que a oferta dessas aumentou na grade curricular em implementação.

Houve um aumento de horas e de disciplinas no currículo atual (4.203 h, 59 disciplinas) em relação ao currículo anterior ( 4.100 h, 46 disciplinas), em grande parte devido à inserção de 420 horas de extensão (eixo didático Geologia e Sociedade) e inclusão de horas nas disciplinas optativas, que eram 150 e passam a 240 horas (Fig. 1). Além disso, as disciplinas de extensão $(420 \mathrm{~h}$ ) e as atividades complementares $(60 \mathrm{~h})$ estão contabilizadas em horas de prática de laboratório, ampliando a sua expressividade nesse gráfico. Em relação aos eixos didáticos (Fig. 2), há redução de horas pertencentes aos eixos de Formação Básica, Fundamentação Profissional Geral e Fundamentação em Geociências no currículo atual, diferentemente do eixo de Geologia e Sociedade que ocorre somente nessa grade.

Apesar do aumento de horas totais no currículo atual, houve diminuição nas horas teórico-práticas de $4.100 \mathrm{~h}$ do currículo anterior para $3.783 \mathrm{~h}$ do currículo atual, o que fez com que muitas disciplinas perdessem horas teóricas e práticas de laboratório e de campo. As atividades de campo tiveram pequena redução no número de horas, de $1006 \mathrm{~h}$ para 978 h no currículo atual, porém ainda cumprem as exigências das DCNs (Fig. 1). 

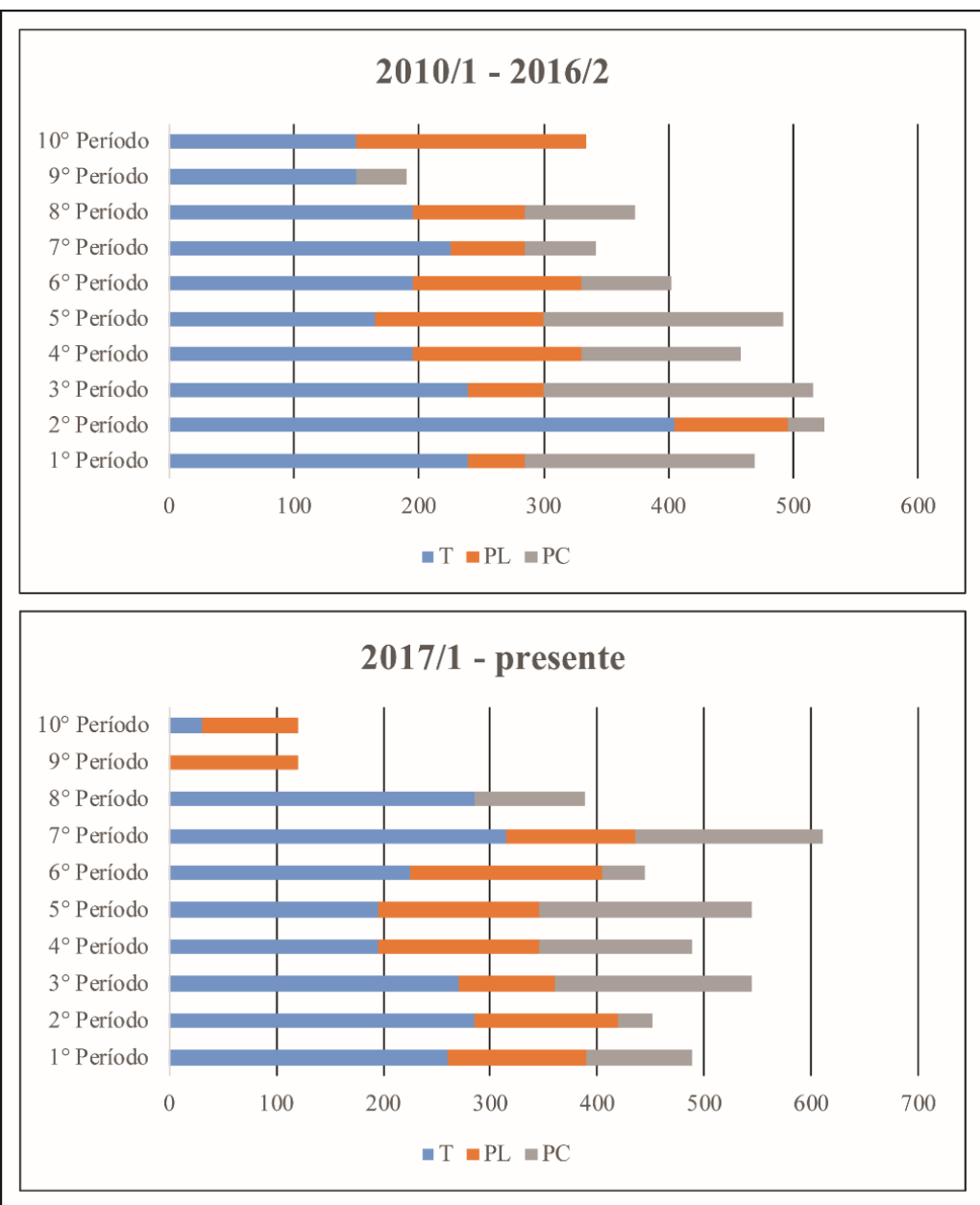

Figura 1. Diagramas comparativos do currículo anterior e atual em relação ao total de horas teóricas, práticas de laboratório e prática de campo ao longo dos dez períodos que compõem o curso de graduação em Geologia da UFRJ. T= carga horária teórica, $\mathrm{PL}=$ carga horária prática de laboratório e $\mathrm{PC}=$ carga horária prática de campo

Os Estágios de Campo (I, II e III) contabilizam 456 h de prática de campo no currículo anterior, correspondendo em cerca de $11 \%$ das horas totais. Entretanto, no currículo atual essas três disciplinas de Estágio de Campo foram substituídas por quatro disciplinas chamadas de Geologia de Campo (I, II, III e IV), que totalizam $456 \mathrm{~h}$ de prática de campo e $90 \mathrm{~h}$ teóricas, correspondendo a $13 \%$ das horas totais. A inclusão de horas teóricas nas disciplinas de campo veio oficializar o que já era feito informalmente, uma vez que os alunos necessitam de preparação e treinamento prévio para realizarem as atividades de campo, bem como acompanhamento pós-campo para elaborarem os relatórios (Compiani \& Carneiro 1993). A disciplina Geologia de Campo I (48 h de prática de campo) foi incluída na nova grade curricular com o objetivo de realizar uma introdução das atividades de campo aos calouros. Também ocorreram mudanças na ordem das atividades de campo e na carga horária, como o Estágio de Campo I passou a ser oferecido como Geologia de Campo III, o Estágio de Campo II é oferecido como Geologia de Campo II e já o Estágio de Campo III como Geologia de Campo IV, apresentando uma redução de $152 \mathrm{~h}$ para $136 \mathrm{~h}$ totais de prática de campo em cada disciplina.

O trabalho de conclusão de curso (TCC) teve uma diminuição de 184 para 90 horas no currículo atual, ambas contabilizadas como horas de prática de laboratório devido ao seu caráter aplicado e prático. No currículo atual, essa disciplina é sugerida para o $10^{\circ}$ período, concomitante ao cumprimento de $30 \mathrm{~h}$ referentes as disciplinas optativas de livre escolha. No currículo anterior, o aluno cumpria 184 h referentes ao TCC, além de $150 \mathrm{~h}$ de atividades acadêmicas optativas, de modo que o desenvolvimento do projeto fosse comprometido em relação a disponibilidade de tempo para sua realização. Apesar disso, o aluno contava com a possibilidade de solicitar essa disciplina no $9^{\circ}$ período e, dessa maneira, ter dois períodos para cumpri-la ao invés de somente um, equilibrando e otimizando sua execução. A realização do TCC em um único período pode ser prejudicial para o desenvolvimento do projeto, principalmente pela questão da administração do tempo com as demais atividades universitárias e pessoais (Oliveira 2003). O aluno terá muitas etapas a serem atingidas nesse processo, como: conseguir um orientador acadêmico no tema de interesse, escrever o projeto, pesquisar na literatura científica nacional e internacional, gerar dados, discuti-los e apresentá-los sob a forma de monografia, que, posteriormente, deverá ser defendida e avaliada por uma comissão formada por docentes e profissionais externos a instituição. A ausência de uma disciplina 


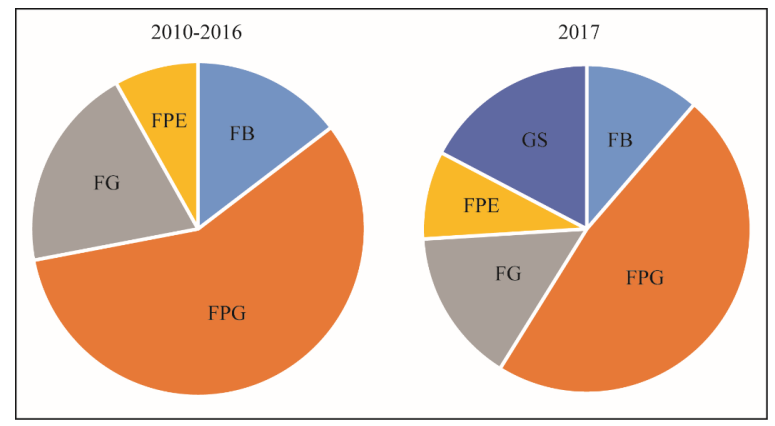

Figura 2. Gráficos referentes aos currículos anterior e atual, mostrando a distribuição de horas por eixo didático. $\mathrm{FB}=$ Formação Básica, FPG= Formação Profissional Geral, $\mathrm{FPE}=$ Formação Profissional Específica, $\mathrm{FG}=$ Fundamentação em Geociências, e GS= Geologia e Sociedade

sobre metodologia científica também é um fator impactante no desenrolar do TCC, pois muitos alunos terão contato com atividades de pesquisa científica sistemática somente na última etapa da graduação e faltará experiência para a realização desse trabalho (Severino 2014). A preparação, redação e apresentação de trabalhos científicos envolvem questões de natureza técnica e estética, dentre as quais, pode-se destacar a disciplina, a criatividade na seleção das referências bibliográficas, a leitura de forma organizada e estruturada, a ousadia e o rigor na abordagem do assunto, além da sistemática do uso de normas de redação e apresentação do texto final (Maia 2008). É necessário que o orientador, além de ensinar e colaborar no trabalho em termos de conhecimento geológico, também auxilie na estruturação da monografia. O TCC deverá permitir ao aluno a aprendizagem de metodologias científicas, o desenvolvimento da capacidade de síntese, o treinamento prático em técnicas de redação de textos técnico-científicos, acelerando, assim, o processo de maturidade científica e profissional (Assine 1994).

Existem formatos de trabalho de conclusão diferentes em outras IES, como descrito por Menegat et al. (2014), que expõem de forma detalhada o Projeto Temático em Geologia (PTGeo) implementado na Universidade Federal do Rio Grande do Sul (UFRGS) desde 2000, do qual divide-se em três etapas (I, II e III) com respectivas disciplinas no $8^{\circ}, 9^{\circ}$ e $10^{\circ}$ período. De acordo com Menegat et al. (op. cit.), as três disciplinas representam três estágios da produção do trabalho: (a) submissão do projeto, realizada na disciplina de PTGeo I; (b) desenvolvimento do trabalho e obtenção de dados no campo e em laboratório, realizada na disciplina de PTGeo II; e (c) síntese dos resultados, finalização da redação de uma monografia e defesa por meio de uma banca, realizada na disciplina de PTGeo III. Os projetos temáticos são desenvolvidos individualmente e o aluno deve demonstrar capacidade de formular problemas e apresentar soluções dentro de uma estruturação técnico-científica de nível superior ao modelo anterior denominado de Trabalho de Graduação (TG), do qual consistia em um mapeamento geológico em grupos. O acompanhamento do projeto nas suas diferentes etapas permite que o aluno sistematize seu projeto e consiga cumprir todas as etapas com êxito.

\section{Possíveis impactos no perfil do egresso: análise das entrevistas}

A definição do perfil do geólogo, segundo Fortes (1995), deve contemplar tanto aspectos estritamente técnico-científicos como sociais, no sentido de capacitar os alunos para que desempenhem seu papel como profissionais e cidadãos dentro da realidade brasileira. Sobre o perfil do egresso, as DCNs definem competências e habilidades que a IES deve proporcionar aos seus discentes, do qual constam detalhadamente descritos no Parecer CNE/CES n ${ }^{\circ}$ 387/2012 (Brasil 2012) e na Resolução CNE/CES 1/2015 (Brasil 2015). As entrevistas estruturadas foram essenciais para entender como foi construída e implementada a grade curricular atual e identificar quais os possíveis impactos no perfil do egresso formado por essa instituição. Os principais temas discutidos nas entrevistas foram organizados em duas categorias que serão apresentadas a seguir.

\section{Diminuição de horas teórico-práticas}

Em relação à diminuição de horas teórico-práticas do currículo atual, o entrevistado A diz "não haver prejuizo para os discentes, pois houve apenas uma adequação da carga horária para oferecer somente o que é necessário à formação do profissional geólogo e possibilitar que o aluno tenha mais horas de trabalho/estudo extraclasse". Nas horas extraclasse, o discente pode aprofundar seus estudos, participando das pesquisas institucionais como aluno de iniciação científica e das atividades de extensão. Dessa forma, o estudante torna-se responsável por sua aprendizagem e por sua profissionalização; para isso, precisará desenvolver e aprimorar seus hábitos de estudo, no que tange a planejamento, definição dos objetivos 
realistas, pontualidade, organização da matéria e revisão sistemática (Gil 2015).

Entretanto, o entrevistado B tem opinião contrária a essas pesquisas, pois diz que "haverá prejuizo para formação do profissional, uma vez que a redução de horas teórico-práticas impactará na construção do conhecimento e das habilidades profissionais, restando ao discente a tarefa de se qualificar sem o apoio universitário". O mesmo entrevistado ressalta também que "as disciplinas de Mineralogia e Petrologias não deveriam ter suas cargas horárias reduzidas, pois isso impactará negativamente na construção da base conceitual geológica". A resposta deste entrevistado mostra diferenças nos modelos epistemológicos e nas práticas pedagógicas adotadas pelos docentes da IES. O entrevistado está apoiado fortemente em uma prática diretiva, na qual o professor é o único responsável pela aprendizagem do aluno (Becker 2012), diferentemente dos demais entrevistados que já possuem uma visão mais relacional da interação aluno-professor.

O entrevistado C espera que "a grade curricular atual possibilite uma melhor formação profissional para seus egressos, uma vez que houve otimização da distribuição das disciplinas e de carga horária teórico-prática”. A organização curricular exerce grande influência, pois é necessário pensar nas dinâmicas de construção da profissão como redes complexas, que levem a novas concepções sobre as disciplinas, a relações interdisciplinares, à formação de competências e à concepção de formação profissional (Ramalho et al. 2004). Os conteúdos curriculares, como proposto no Parecer CNE/CES no 387/2012 (Brasil 2012) devem contemplar a formação básica e profissional do geólogo, adicionando conteúdos temáticos que poderão ser estabelecidos de acordo com os objetivos das instituições de ensino e em atendimento às demandas do contexto regional.

Alguns problemas na execução da grade curricular nova no sistema online da UFRJ foram apontados pelos entrevistados como relação ao número, códigos e pré-requisitos das disciplinas. De acordo com o entrevistado E, para o processo de implementação "foram retirados alguns pré-requisitos das disciplinas a fim de que o sistema funcione com a concomitância das duas grades curriculares, pois discentes ingressos antes de 2017 permanecem com a grade curricular anterior". Segundo o mesmo entrevistado, "as disciplinas da grade curricular anterior não serão mais oferecidas, dessa maneira, haverá equivalência dessas com a da grade curricular em implementação, não causando prejuízo para o discente". A IES, de acordo com E-MEC (2017), tem autonomia para modificar a grade curricular do curso, devendo esta alteração ser aprovada pelo colegiado superior da instituição e ser registrada em ata. Além disso, ressalta que o aluno não tem direito adquirido em relação à grade curricular, isto é, não é obrigatório que a grade curricular inicialmente proposta não se altere ao longo do curso (E-MEC 2017). Assim, cabe a IES decidir a forma de coexistência e equivalência das duas grades curriculares.

As atividades profissionais de um geólogo são inicialmente técnicas, passando posteriormente a técnicas e administrativas e, para alguns, evolui para as de direção e planejamento (Assine 1994). Algumas sugestões curriculares para preparar o profissional para as diferentes fases da carreira foram apontadas por alguns entrevistados. O entrevistado $\mathrm{C}$ sugere para as futuras revisões curriculares que ocorra "a inserção de disciplinas de gestão e empreendedorismo, como também administração, com intuito de preparar os profissionais para o mercado de trabalho".

\section{Inclusão de atividades de extensão e novas disciplinas}

A universidade, como instituição educativa, tem por finalidade a produção do conhecimento, por meio da problematização dos conhecimentos historicamente produzidos, de seus resultados na construção da sociedade humana e das novas demandas e desafios que ela apresenta (Pimenta \& Anastasiou 2014). Esta, por sua vez, está sustentada pelo tripé Ensino, Pesquisa e Extensão. A extensão universitária tem um papel importante, pois permite ao aluno colocar em prática aquilo que aprendeu em sala de aula e desenvolvê-lo fora dela (Rodrigues et al. 2013). Sobre as atividades de extensão curriculares inseridas, os entrevistados apontam que os principais problemas para a realização são a dotação orçamentária, o engajamento dos colaboradores (principalmente os discentes) e a infraestrutura para a execução dos projetos. Sobre a dotação orçamentária, o entrevistado C diz que "tudo dependerá de projetos paralelos para a captação de recursos com empresas públicas e privadas, como também órgãos públicos”. As atividades de extensão oferecidas pelo Departamento de Geologia abordam, segundo o entrevistado D, "temas variados, desde divulgação científica a curadoria de coleções geológicas". Contudo, somente o entrevistado E diz "desconhecer as ações de extensão que estão sendo realizadas no departamento de Geologia, embora esteja ciente da sua importância para a progressão na carreira docente". É necessário que a UFRJ provenha aos seus servidores vivências e trei- 
namentos nas atividades de extensão oferecidas no Departamento, bem como explicar sua importância e significado dentro da instituição e da sociedade.

O entrevistado C acredita que "o egresso sairá com maior responsabilidade social e de cidadania devido ao seu envolvimento com as atividades de extensão". Em contrapartida, o entrevistado D já observa "o baixo interesse dos discentes na participação das atividades propostas". Frente a esta consideração, cabe observar que é imprescindível que o docente juntamente com o Departamento de Geologia desenvolva atividades e práticas que motivem e despertem a participação discente. O ponto de partida da motivação para aprender deve estar, de acordo com Gil (2015), no reconhecimento por parte do estudante de que tem a necessidade de aprender, pois é ela que desperta seu organismo para a ação, ou seja, para o conhecimento. Diante disso, o referido autor considera que não se pode afirmar que é o professor que motiva os estudantes a aprender. Porém, faz recomendações aos docentes para estimularem o aprendizado da seguinte forma: procure variar o formato das aulas; proponha tarefas de dificuldade moderada, pois elas motivam mais que as de maior dificuldade, aplique o reforço positivo e negativo para os comportamentos, entre outras recomendações.

Em relação ao Estágio Supervisionado, o entrevistado A diz que "essa atividade não será viável para todos os discentes, em razão da baixa oferta de oportunidades nas empresas privadas e instituições públicas por causa da atual crise econômica brasileira”. Já o entrevistado D diz que "a obrigatoriedade do estágio pode trazer problemas, pois muitos alunos podem atrasar suas formaturas diante da dificuldade de realizar a atividade”. Porém, ambos ressaltam importância dessa atividade na construção do profissional geólogo. $\mathrm{O}$ entrevistado B diz que "os benefícios da inclusão do estágio são muitos, pois permitem uma real aproximação dos discentes com as condições e demandas da profissão, mas hoje exigem uma total readequação do curso para que possamos executar tal atividade com êxito”. Está de acordo com essa opinião o entrevistado C, que diz "se realizado (estágio) em empresa é um ganho muito grande, pois o aluno aprende a dinâmica de trabalho e as relações interpessoais no ambiente profissional. Porém, o estado tem três cursos de geologia, essa oferta não atende a todos. Muitas dessas atividades terão que serem feitas/ cumpridas dentro da própria universidade”. O processo de profissionalização, segundo o Parecer CNE/CES n $387 / 2012$ (Brasil 2012), é constituído de etapas que podem levar anos, ocorrendo posteriormente com a realização de diversas atividades na profissão, normalmente acompanhadas por um profissional sênior. O docente deve realizar acompanhamento desta atividade, uma vez que é supervisionada, com a dupla função de exigir do aluno dedicação e responsabilidade e evitar que as empresas utilizem os estágios como uma forma de apenas conseguir mão de obra barata (Assine 1994).

Houve uma unanimidade nas respostas dos entrevistados em relação a disciplina de Saúde e Segurança em Atividades de Geologia, indicando que a sua inclusão, conforme o entrevistado D, "trará grandes benefícios para a conscientização das responsabilidades e da sistemática para a execução segura das atividades de campo, pois habilita o reconhecimento de riscos e a compreensão da importância do uso dos Equipamentos de Proteção Individual (EPI) tanto por parte dos discentes quanto dos docentes”. Essa discussão, segundo o mesmo entrevistado, "está sendo levada a outras instâncias da Universidade com o objetivo da elaboração de uma legislação interna, para propiciar a solicitação de verbas orçamentárias para a compra e manutenção dos EPIs”. Essa preocupação com a segurança e procedimentos das atividades de campo da graduação em Geologia já era latente nas discussões do Fórum Nacional de Cursos de Geologia (e.g. Carneiro, 2005a, 2005b, 2014; Carneiro \& Assis, 2006; Menegat \& Carneiro, 2014), do qual foram significativas para a construção das DCNs (Brasil 2015) e mostram que a visão sobre as atividades de campo vem lentamente se modificando, ou seja, tornando-se mais profissional e responsável (Menegat \& Carneiro 2014).

De acordo com Menegat \& Carneiro (2014), a segurança nas atividades de ensino de campo advém de um conjunto de medidas, que incluem preparação dos participantes por meio de seminários prévios, planejamento detalhado da logística das atividades, escolha de áreas apropriadas para o ensino de campo, duração das atividades e equipe de trabalho de campo adequado ao número de participantes. Os autores supracitados também evidenciam a importância do uso de instrumentos de avaliação de riscos e adoção de protocolos de segurança típicos que evidenciem a ciência dos riscos envolvidos bem como as medidas preventivas adotadas pelos participantes das atividades de campo. Portanto, as IES precisam de apoio de modo a contar com recursos financeiros e infraestrutura que as habilitem a desenvolver os trabalhos de campo (Carneiro 2014) de modo seguro, seguindo as normas de saúde e segurança (e.g. uso dos EPIs e seguro de vida para discentes e docentes).

Em relação as atividades de campo, o entre- 
vistado D diz que "a inclusão de horas teóricas nas disciplinas Geologia de Campo (I, II, III e IV) se deve à adequação e formalização de horas para a preparação dos alunos nas etapas pré-campo e pós-campo". As atividades de campo em Geologia são importantes no ensino e aprendizagem de conceitos geológicos. Entre os distintos papéis didáticos, Carneiro \& Campanha (1979, apud Compiani \& Carneiro 1993) propõem que as atividades de campo na Geologia desempenham quatro categorias: (i) ilustrativa, cujo objetivo é ilustrar os conceitos abordados em sala de aula; (ii) motivadora, motivar o aluno a estudar e aprender sobre o tema, (iii) treinadora, que visa a orientar a execução de uma habilidade técnica; e (iv) geradora de problemas, que orienta o aluno a resolver ou propor um problema. Os trabalhos de campo devem ser direcionados no sentido de aguçar a capacidade de observação dos alunos e formulação de hipóteses de trabalho (Assine 1994).

\section{Considerações Finais}

As Diretrizes Curriculares Nacionais para os cursos de graduação em Geologia e Engenharia Geológica propõem indicações básicas e gerais da estrutura curricular que cada IES deve conter, porém permitem maior autonomia para que estas formulem seus projetos pedagógicos em vista de manter a identidade regional de cada curso. A grade curricular atual em fase de implementação no curso de graduação em Geologia da UFRJ cumpre todos os requisitos das DCNs, mostrando-se com caráter generalista, porém com uma estrutura mais integrada e proporcionando maior conscientização social ao discente do que a grade curricular anterior. A estruturação em eixos didáticos traz ao currículo atual um caráter dinâmico, pois os alunos desde o início do curso têm contato com as disciplinas mais específicas e não somente disciplinas básicas e de fundamentação. Observa-se também uma modernização no que diz respeito ao encadeamento e ordem das disciplinas oferecidas ao longo do curso, possibilitando um melhor enlaçamento dos conteúdos e melhor aprendizagem.

Os impactos positivos esperados para o perfil do egresso, de acordo com a análise das grades curriculares e entrevistas realizadas com parte do corpo docente, consistem na melhor preparação do profissional geólogo para o mercado de trabalho devido à inclusão do Estágio Supervisionado e da disciplina de Saúde e Segurança em Atividades de
Geologia, além de proporcionar uma mudança no perfil do egresso com a formação de profissionais mais autônomos, criativos e preocupados com os problemas sociais e ambientais.

No entanto, os impactos negativos esperados são relacionados a: (1) baixa aderência às atividades de extensão por parte dos discentes e docentes, fazendo com que o discente egresso seja indiferente às questões sociais e (2) diminuição de horas de algumas disciplinas dos eixos de Fundamentação em Geociências e de Formação Profissional Geral, que poderá causar prejuízo na formação do profissional, pois faltará base conceitual para o entendimento e resolução de problemas geológicos mais complexos.

Portanto, os docentes devem estar conscientes da necessidade das mudanças curriculares para a adequação do curso de Geologia às novas demandas profissionais e sociais, ou seja, o envolvimento e comprometimento do docente com a educação é um fator primordial para a construção profissional do discente. $\mathrm{O}$ docente pode contribuir com a reavaliação e a readequação dos conteúdos das suas respectivas disciplinas do currículo atual, bem como contribuir com as atividades de extensão de maneira a incentivar a participação ativa dos discentes nas propostas. O preparo do docente em relação ao conteúdo e metodologia de ensino contribuirá enormemente para as mudanças no perfil do egresso, pois tornará as aulas ministradas mais interessantes e apropriadas para o entendimento do conhecimento geológico proposto em cada etapa da grade curricular em implementação. Para isso, aponta-se a necessidade da criação de políticas universitárias que proporcionem treinamento e atualização contínua do professor universitário em face aos diferentes perfis de discentes ingressantes na atualidade, como também aumentar a versatilidade nas novas formas de ensinar e aprender.

Sugere-se um acompanhamento semestral de todo processo de implementação a fim de que se possam detectar inconsistências na grade curricular, como também planejar possíveis revisões curriculares periódicas. Adicionalmente, espera-se que, com a implementação do currículo atual de acordo com as DCNs, a grade curricular continue a ser pensada de maneira holística em relação às competências e atribuições profissionais, para que o discente tenha possibilidade de integrar os conhecimentos adquiridos e desenvolvidos ao longo dos dez semestres de curso de forma articulada às necessidades do mercado de trabalho e da sociedade. 


\section{Agradecimentos}

Ao Dr. Aristóteles de Moraes Rios Netto e Dr. Marco Antônio Braga pelo acesso aos dados curriculares e ao PPC do curso. Aos docentes do curso de Geologia da UFRJ pela participação e colaboração nas entrevistas. Especial agradecimento ao MSc. Jaques Schmidt pela revisão final.

\section{Referências}

Almeida M.I., Pimenta S.G. 2014. Estágios supervisionados na formação docente. São Paulo: Cortez. 160 p.

Assine M.L. 1994. Repensando os cursos de graduação em Geologia. Cadernos IG-Unicamp, 4(1):34-65.

Assis J.F.P., Fantinel L., Carneiro C.D.R. 2008. Relato Final do VI Encontro do Fórum Nacional de Cursos de Geologia. Terre Didatica, 4(1):67-77. URL: https://periodicos.sbu.unicamp.br/ojs/index. $\mathrm{php} / \mathrm{td} /$ article/download/8637495/5200. Acesso 30.09.2017.

Barroso E.V.; Barroso J.A; Horta A.E.D.G.; Carvalho I.S. 2008. 2008: Retrospectiva dos 50 Anos da Geologia na UFRJ e Olhar Crítico para o Futuro. Anuário Inst. Geoc. UFRJ, 31(1):9-23.

Becker F. 2012. Educação e construção do conhecimento: revista e ampliada. $2^{\circ}$ ed. Porto Alegre:Penso. 200p.

Brasil. 1957. Decreto $\mathrm{n}^{\circ} 40.783$, de 18 de janeiro de 1957. Institui a Campanha de Formação de Geólogos. Diário Oficial da União - Seção 1 19/1/1957. URL: http://www2.camara.leg.br/ legin/fed/decret/1950-1959/decreto-40783-18-janeiro-1957-379597-publicacaooriginal-1-pe.html. Acesso 30.09.2017.

Brasil. 2012. Parecer CNE/CES 387/2012. Proposta de Diretrizes Curriculares Nacionais para o curso de graduação em Geologia e em Engenharia Geológica, bacharelados. Diário Oficial da União de 3/7/2014, Seção 1. URL: http:// portal.mec.gov.br/index.php?option $=\mathrm{com}$ docman\&view $=$ download\&alias $=12277-\mathrm{pc}-$ es387-12-pdf\&category_slug=janeiro-2013pdf\&Itemid $=30192$. Acesso 30.09.2017.

Brasil. 2014. Lei Federal n. ${ }^{\circ} 13.005$, de 25 de junho de 2014. Aprova o Plano Nacional de Educação - PNE e dá outras providências. Diário Oficial da União - Seção 1 - Edição Extra - 26/6/2014. URL: http://www2.camara.leg.br/legin/fed/lei/2014/lei13005-25-junho-2014-778970-publicacaooriginal-144468-pl.html. Acesso 30.09.2017.

Brasil. 2015. Resolução no 1, de 6 de Janeiro de 2015. Institui as Diretrizes Curriculares Nacionais para os cursos de graduação na área da Geologia, abrangendo os cursos de bacharelado em Geologia e em Engenharia Geológica e dá outras providências. URL: http://portal.mec.gov.br/ index.php?option $=$ com docman\&view $=$ down load\&alias $=16871$-res-cne-ces-001-06012015\& category_slug=janeiro-2015-pdf\&Itemid $=30192$. Acesso 30.09.2017.

Carneiro C.D.R. 2005a. Relato final do I Encontro do Fórum Nacional de Cursos de Geologia. Terre Didatica, 1(1):70-73. URL: https://www.ige.unicamp. br/terraedidatica/v4/pdf-v4/pdf-v4-art7bis.pdf.
Acesso 30.09.2017.

Carneiro C.D.R. 2005b. Relato final do II Seminário Nacional sobre Cursos de Graduação em Geologia. Terre Didatica, 1(1):55-63. URL: https://www. ige.unicamp.br/terraedidatica/v1/pdf-v1/p055063 carneiro.pdf. Acesso 30.09.2017.

Carneiro C.D.R. 2014. O Fórum Nacional de Cursos de Geologia e as Diretrizes Curriculares Nacionais : histórico e perspectivas. Terra Didatica, 10:191203. URL: https://periodicos.sbu.unicamp.br/ojs/ index.php/td/article/view/8637316/5032. Acesso 30.09.2017.

Carneiro C.D.R., Assis J.F.P. 2005. Relato final do II Encontro do Fórum Nacional de Cursos de Geologia. Terree Didatica, 1(1):74-83. URL: https:// www.ige.unicamp.br/terraedidatica/v1/pdf-v1/ p074-083_carneiro_assis.pdf. Acesso 30.09.2017.

Carneiro C.D.R., Assis J.F.P. 2006. Relato final do IV Encontro do Fórum Nacional de Cursos de Geologia. Terre Didatica, 2(1):86-90. URL: https:// www.ige.unicamp.br/terraedidatica/v2/pdf-v2/t didatica_2006_v02n01_p086-090_carneiro_assis. pdf. Acesso 30.09.2017.

Carneiro C.D.R., Campanha G.A. 1979. O ensino de campo em geologia. In: Curso de Especialização em Ensino Superior de Geociências, 1, Belém, 1979. Apostila...Belém: UBPa.

Carneiro C.D.R., Menegat R., Janasi V.A. 2014. Implicações práticas das diretrizes curriculares de Geologia e Engenharia Geológica no Brasil. Com. Geol., 101(Esp. III): 1215-1218.

Compiani M., Carneiro C.D.R. 1993. Os papéis didáticos das excursões geológicas. Ens. Cien. Tierra, 1(2):90-98.

E-MEC. 2017. Tramitação eletrônica dos processos de regulamentação. Brasília: MEC. URL: http://portal.mec. gov.br/e-mec-sp-257584288. Acesso 19.09.2017.

Fantinel L., Janasi V.A., Assis J.F.P., Alecrim J.R., Almeida H.L., Compiani M., Conceição R., Duarte B.P., Fauth G., Fonseca V.P., Fortes P., Leite Júnior W.B., Mancini F., Menezes M.G., Silva C.H., Silva Filho W., Velloso E., Carneiro C.D.R. 2008a. Diretrizes Curriculares para os Cursos de Graduação em Geologia e Engenharia Geológica. Terre Didatica, 4(1):85-89. URL: https://www.ige.unicamp.br/ terraedidatica/v4/pdf-v4/pdf-v4-art8.pdf\%0A. Acesso 28.09.2017.

Fantinel L., Janasi V.A., Assis J.F.P., Carneiro, C.D.R. 2008b. Relato Final do VII Encontro do Fórum Nacional de Cursos de Geologia. Terre Didatica, 4(1):81-84. URL: https://periodicos.sbu.unicamp. br/ojs/index.php/td/article/view/8637497. Acesso 30.09.2017.

Fortes P.T.F.O. 1995. Mudanças no currículo do curso de graduação em geologia da Universidade de Brasília: um convite à reflexão. Cadernos IG/UNICAMP, 5(2):3-21.

Gil A.C. 2008. Métodos e técnicas de pesquisa social. São Paulo: Atlas. 208 p.

Gil A.C. 2015. Didática do Ensino Superior. São Paulo: Atlas. 283 p.

Júnior A.F.B., Júnior N.F. 2011. A utilização da técnica da entrevista em trabalhos científicos. Evidência, 7(7):237-250.

Laville C., Dionne J. 1999. A construção do saber: Manual 
de metodologia da pesquisa em ciências humanas. Porto Alegre: Artmed. 344p.

Maia R.T. 2008. A importância da disciplina de metodologia científica no desenvolvimento de produções acadêmicas de qualidade no nível superior. Rev. Urutágua, (14):1-8.

Menegat R., Mizusaki A.M.P., Remus M., Lelarge L.M.V., Dani N. 2014. Inovação no paradigma curricular: os projetos temáticos em Geologia. Terre Didatica, 10(3):204-216. URL: https://www.ige. unicamp.br/terraedidatica/V10 3/PDF/TDv10-3113.pdf. Acesso 30.09.2017.

Menegat, R., Carneiro, C.D.R. 2014. Síntese das decisões do XIV Encontro do Fórum Nacional de Cursos de Geologia. Terre Didatica, 10(3):474-476. URL: https://www.ige.unicamp.br/terraedidatica/ V10_3/PDF/carta salvador.pdf. Acesso 30.09.2017.

Nummer A.R., Godoy A.M., Lazzarotto A., Carneiro C.D.R., Schultz C.L., Tubbs Filho D., Guimarães E.M., Althoff F., Assis J.F.P., Pinho F.E.C., Sobreira F., Carvalho I.S., Sabadia J.A.B., Fernandes Filho L.A., Toledo M.C.M., Fernandes M.L.S., Costa R.D., Machado R., Menegat R., Nadalin R.J., Santos R.A.A.; Vasconcelos S.M.S., Marques T.M., Souza Z.S. 2005. Diretrizes curriculares para os cursos de graduação em Geologia e Engenharia Geológica. Terre Didatica, 1(1):64-69. URL: http:// geo25.ige.unicamp.br/terraedidatica/v1/pdf-v1/ p064-069_nummer_et_al.pdf. Acesso 30.09.2017.

Oliveira G.A.P. 2003. A concepção de egressos de um Curso de Pedagogia acerca da contribuição do trabalho de conclusão de curso. Campinas: Univ. Est. Campinas, Fac. Educação. 129p. (Dissert. Mestrado). URL: http://libdigi.unicamp.br/document $/$ ?code $=$ vtls000298920. Acesso 30.09.2017.

Pimenta S.G., Anastasiou L.G.C. 2014. Docência no Ensino Superior. São Paulo:Cortez. 280p.

Pimenta S.G., Lima M.S.L. 2012. Estágio e docência. São Paulo:Cortez. 296p.

PPC. 2017. Projeto pedagógico do curso de graduação em geologia. Univ. Fed. do Rio de Janeiro (UFRJ), 2017. $62 \mathrm{p}$.

Ramalho B.L., Nuñez I.B., Gauthier C. 2004. Formar o professor, profissionalizar o ensino: perspectivas e desafios. $2^{\circ}$ ed. Porto Alegre: Sulina. 208p.

Rodrigues A.L.L., Prata M.S., Batalha T.B.S., Costa C.L.N.A., Neto I.F.P. 2013. Contribuições da extensão universitária na sociedade. Cadernos Grad. Cien. Hum. Soc., 1(16):141-148.

Severino A.J. 2014. Metodologia do trabalho científico. São Paulo: Cortez. 320p.

Sobreira F. 2005. Relato final do I Seminário Nacional sobre Cursos de Graduação em Geologia: Salvador, maio de 2001. Terre Didatica, 1(1):51-54. URL: http://ppegeo.igc.usp.br/index.php/TED/ article/view/8179/7457. Acesso 30.09.2017. 